\title{
Mapeamento de QTL nos cromossomos 1, 2, 3, 12, 14, 15 e X em suínos: características de carcaça e qualidade de carne
}

\author{
[Mapping of QTL on chromosomes 1, 2, 3, 12, 14, 15 and $X$ in pigs: characteristics \\ carcass and quality of meat] \\ D.M. Paixão ${ }^{1}$, P.L.S. Carneiro ${ }^{1}$, S.R. Paiva ${ }^{2}$, K.R.S. Sousa ${ }^{1}$, L.L. Verardo ${ }^{1}$, \\ J. Braccini Neto ${ }^{1}$, A.P.G. Pinto ${ }^{1}$, A.M. Hidalgo ${ }^{1}$, C. Souza do Nascimento ${ }^{1}$, \\ I.V. Périssé ${ }^{3}$, P.S. Lopes ${ }^{4}$, S.E.F. Guimarães ${ }^{4 *}$ \\ ${ }^{1}$ Alunos de pós-graduação - Universidade Federal de Viçosa - Viçosa, MG \\ ${ }^{2}$ Empresa Brasileira de Pesquisa Agropecuária- DF \\ ${ }^{3}$ Aluno de graduação - Universidade Federal de Viçosa - Viçosa, MG \\ ${ }^{4}$ Universidade Federal de Viçosa - Viçosa, MG
}

\begin{abstract}
RESUMO
A realização do presente estudo teve como objetivo mapear Quantitative Trait Loci (QTL) de carcaça e qualidade de carne em uma população F2 de suínos desenvolvida pelo cruzamento de dois reprodutores da raça brasileira Piau com 18 fêmeas comerciais (Landrace x Large White x Pietrain). O mapa de ligação para essa população foi construído após a genotipagem de 684 animais para 35 marcadores microssatélites. Os dados foram analisados pelo mapeamento por intervalo usando-se sexo, lote e genótipo halotano como efeitos fixos e peso de carcaça ao abate, peso da carcaça direita e idade ao abate como covariáveis. Um total de 18 QTLs foi encontrado; os QTLs para maior espessura de toucinho na região da copa, na linha dorsolombar, e a perda por cozimento foram significativos em nível de 5\% genômico. A característica espessura de toucinho foi essencialmente associada aos alelos da raça Piau, conhecido como porco tipo banha. As informações dos QTLs significativos encontrados servem para futuros estudos de mapeamento fino para identificação de genes a serem usados em conjunto com os métodos tradicionais de seleção, para melhorar a eficiência dos programas de melhoramento, assim como prover informação acerca da fisiologia envolvida no desenvolvimento das características quantitativas dos suínos.
\end{abstract}

Palavras-chave: suínos, raça Piau, marcador molecular, microssátelites

\begin{abstract}
The accomplishment of the present study had as objective to map Quantitative Trait Loci (QTL) associated to carcass and quality traits in a F2 pig population developed by mating two Brazilian Piau breed sires with 18 dams from a commercial line (Landrace $\times$ Large White $\times$ Pietrain). The linkage map for this population was constructed after genotyping the 684 animals for 35 microsatellite markers. Data were analyzed by interval mapping using sex, batch and halothane genotype as fixed effects and carcass weight at slaughter, direct carcass weight and slaugher age as covariables. A total of 18 QTL were identified, the QTL for higher backfat thickness on the shoulder region and cooking loss was significant at 5\% genome-wise level. The backfat thickness trait was mainly associated with the Piau breed allele, known as a fat pig. The information of the significant QTL detected in this study is useful for future finemapping studies for identification of genes and might be used together with traditional selection methods to improve the efficiency of breeding programs, moreover, this information can also provide new insights to the understanding of the physiology of the quantatiative traits in pigs.
\end{abstract}

Keywords: pigs, Piau breed, molecular marker, microsatellites

Recebido em 2 de abril de 2011

Aceito em 13 de abril de 2012

*Autor para correspondência (corresponding author)

E-mail: sfacioni@uvf.br

Apoio financeiro: CAPES, CNPq, FAPEMIG e INCT - Ciência Animal 


\section{INTRODUÇÃO}

Há décadas, a indústria de suínos procura por carcaças com alto rendimento de carne e alta estabilidade durante a estocagem. Além disso, os aspectos avaliados entre os consumidores são, principalmente, cor, maciez, odor e reduzida espessura de toucinho na carne.

A variação genética das características de importância econômica em suínos tem a sua origem nas diferenças entre raças ou linhas, efeitos dos genes e suas interações, e herdabilidades. Uma estratégia para determinar os locos gênicos envolvidos no controle dessas características quantitativas são os estudos por meio de associações estatísticas entre marcadores genéticos e a característica de interesse (QTL), sendo de grande aplicabilidade como informações adicionais aos programas tradicionais de seleção.

As raças naturalizadas brasileiras tiveram sua origem nas raças introduzidas pelos colonizadores portugueses no século XVI. O suíno Piau é uma dessas raças e é caracterizado por baixo desempenho, pequeno tamanho de leitegada, rusticidade, adaptabilidade a condições pobres de manejo e alimentação e destaca-se pelo grande acúmulo de gordura subcutâneo (Guimarães e Lopes, 2001).

Neste sentido, objetivou-se com este trabalho mapear QTLs associados a características de carcaça e qualidade de carne, nos cromossomos SSC1, SSC2, SSC3, SSC12, SSC14, SSC15 e SSCX de suínos de uma população F2 proveniente do cruzamento de machos da raça naturalizada Piau e fêmeas de linhagem comercial. Deste modo, pretende-se concluir o mapeamento dos 18 cromossomos autossômicos e do cromossomo sexual X nessa população.

\section{MATERIAL E MÉTODOS}

A formação da população $\mathrm{F} 2$ e a coleta dos dados fenotípicos foram realizadas na Granja de Melhoramento de Suínos do Departamento de Zootecnia da Universidade Federal de Viçosa (UFV), em Viçosa, Minas Gerais, Brasil, no período de novembro de 1998 a julho de 2001. Foram construídas, inicialmente, duas famílias provenientes do cruzamento de dois varrões da raça naturalizada brasileira Piau com 18 fêmeas originadas de linhagem comercial desenvolvida na UFV, selecionada para desempenho (Landrace $\times$ Large White $\times$ Pietrain). Maiores detalhes sobre a constituição da população foram descritos por Band et al. (2005a,b) e Peixoto et al. (2009).

Os marcadores microssatélites foram testados em relação a sua amplificação e informatividade, de forma que 35 marcadores foram selecionados para mapear os cromossomos 1, 2, 3, 12, 14, $15 \mathrm{e}$ X. As amplificações do DNA de 20 animais parentais, 64 animais $\mathrm{F} 1$ e, em média, 400 animais F2 foram feitas no Laboratório de Genética Animal (LGA), da Embrapa Recursos Genéticos e Biotecnologia, Brasília-DF, em termocicladores MJ Research PTC 100-96, usando-se QIAGEN Multiplex PCR Kit (Qiagen, Valencia, C.A., EUA). A declaração dos alelos foi feita utilizando-se o software GenScan e Genotyper (Applied Biosystems, Foster City, C.A., EUA). A eletroforese capilar foi realizada por meio de sequenciador automático $\mathrm{ABI}$ PRISM 3700.

As informações contidas em cada loco, bem como o grau de polimorfismo deles (PIC), foram computadas por meio do software CERVUS versão 3.0 (Kalinowski et al., 2007). Para construção do mapa de ligação dos seis cromossomos autossômicos e o sexual X, utilizou-se o software CRIMAP versão 2.4 (Green et al., 1990). Os dados de genótipo, fenótipo e o mapa de ligação gerados foram submetidos ao software GridQTL (Seaton et al., 2006) para detecção de QTL.

A determinação dos limiares de significância cromossômica $(\alpha=0,05$ e $\alpha=0,01)$ foi feita no software GridQTL, com 10.000 permutações (Churchill e Doerge, 1994), e foi representada por $\mathrm{Pc}<0,01$ e $\mathrm{Pc}<0,05 \quad(1 \%$ e $5 \%$, respectivamente). Os limiares genômicos foram obtidos por meio da correção de Bonferroni (Knott et al., 1998). O intervalo de confiança a 95\% (IC95\%) para a localização do QTL foi obtido usando-se a aproximação de qui-quadrado $\left(\chi^{2}\right)$, e a fração aditiva da variância fenotípica $\left(h_{Q}^{2}\right.$ ) explicada pelo QTL foi feita conforme descrito por Pérez-Enciso et al. (2000). As covariáveis usadas foram: o peso da carcaça no abate para as características carcaça; o peso da 
carcaça direita para as características de corte; e idade ao abate para as características de qualidade. Maiores detalhes sobre as características analisadas e as análises estatísticas foram descritos por Paixão et al. (2008a,b).

\section{RESULTADOS E DISCUSSÃO}

Foram utilizados 35 marcadores microssatélites para o mapeamento dos QTLs em 534 animais: 20 animais parentais, 64 animais $\mathrm{F} 1$ e, em média, 450 animais F2. Informaçoes sobre os microssátelites, como número de alelos e conteúdo de informação polimórfica (PIC), estão apresentadas na Tab. 1.

A distância média entre os marcadores foi de 30 cM, explicada pela dificuldade de se identificar marcadores polimórficos em algumas regiões dos cromossomos avaliados na população estudada. Com exceção do SSC1, que foi mapeado a partir da região central do cromossomo, o restante dos cromossomos apresentaram mapas, de acordo com o mapa do USDA-ARS, considerado como referência

(http://www.marc.usda.gov/genome/swine/swine .html).

Tabela 1. Identificação do marcador, posição nos cromossomos de suínos, número de alelos segregantes e conteúdo de informação polimórfica (PIC) de cada microssátelite mapeado

\begin{tabular}{ccccc|ccccc}
\hline Marcador & Chr $^{1}$ & Pos $^{2}$ & Alelos & PIC & Marcador & Chr $^{1}$ & Pos $^{2}$ & Alelos & PIC \\
\hline SW781 & 1 & 55 & 3 & 0,44 & SW1962 & 12 & 91 & 4 & 0,60 \\
SW2035 & 1 & 71 & 4 & 0,60 & S0106 & 12 & 113 & 7 & 0,81 \\
S0113 & 1 & 80 & 3 & 0,54 & SW857 & 14 & 0 & 7 & 0,78 \\
SWR982 & 1 & 84 & 3 & 0,56 & SW210 & 14 & 45 & 6 & 0,56 \\
S0112 & 1 & 120 & 4 & 0,63 & SW761 & 14 & 86 & 4 & 0,44 \\
SW2423 & 2 & 0 & 6 & 0,79 & SW2515 & 14 & 125 & 5 & 0,48 \\
SW240 & 2 & 48 & 7 & 0,70 & S0355 & 15 & 0 & 4 & 0,43 \\
SW395 & 2 & 70 & 5 & 0,66 & S0004 & 15 & 29 & 3 & 0,39 \\
SW1883 & 2 & 98 & 3 & 0,35 & SW1989 & 15 & 64 & 6 & 0,69 \\
S0036 & 2 & 150 & 4 & 0,67 & SW1316 & 15 & 88 & 5 & 0,71 \\
SW2021 & 3 & 0 & 6 & 0,75 & SW936 & 15 & 100 & 5 & 0,74 \\
S0206 & 3 & 39 & 5 & 0,59 & SW1262 & 15 & 130 & 3 & 0,51 \\
SW902 & 3 & 65 & 4 & 0,57 & SW949 & X & 0 & 6 & 0,63 \\
S0002 & 3 & 112 & 7 & 0,79 & SW980 & $X$ & 15 & 4 & 0,48 \\
SW717 & 3 & 134 & 4 & 0,63 & SW2126 & X & 38 & 3 & 0,52 \\
SW2494 & 12 & 0 & 3 & 0,45 & SW1943 & X & 90 & 3 & 0,49 \\
SW957 & 12 & 24 & 6 & 0,64 & S0218 & $X$ & 120 & 3 & 0,38 \\
SW168 & 12 & 61 & 4 & 0,68 & & & & & \\
\hline
\end{tabular}

${ }^{\mathrm{T}} \mathrm{Chr}=$ cromossomo $;{ }^{2} \mathrm{Pos}=$ posição em cM.

Todos os marcadores utilizados neste trabalho podem ser considerados eficientes nos estudos de características quantitativas, pois a aplicabilidade dos marcadores possui relação direta com o grau de polimorfismo deles (Tab. 1). Os marcadores do presente estudo foram classificados como moderadamente polimórficos, com 0,25>PIC $>0,5$, ou considerados altamente polimórficos, com PIC>0,5 (Botstein et al., 1980).
Os limiares de significância para testar o modelo com efeito aditivo e de dominância foram de $8,30 \quad(\mathrm{P}<0,05)$ e $10,06 \quad(\mathrm{P}<0,01)$, para os cromossomos autossômicos, e de $13(\mathrm{P}<0,05)$ e $16,35(\mathrm{P}<0,05)$, para o cromossomo sexual. Sete QTLs foram encontrados associados a diferentes características de carcaça, cinco QTLs para características de corte de carcaça e seis QTLs para características de qualidade de carne (Tab. 2). Desses 18 QTLs, encontrou-se um para perda de cozimento (PCOZ) no SSC1, significativo em nível de 5\% genômico. 
Mapeamento de QTL nos cromossomos...

Tabela 2. Informações sobre os QTLs significativos encontrados: efeitos aditivos (a), de dominânica (d), erro-padrão (EP), variância aditiva do QTL $\left(\mathrm{h}^{2}{ }_{\mathrm{q}}\right)$ e intervalo de confiança

\begin{tabular}{|c|c|c|c|c|c|c|c|}
\hline Cromossomo & Características ${ }^{1}$ & $\mathrm{~F}$ & $\operatorname{Pos}^{2}$ & $a^{3}(E P)$ & $\mathrm{d}(\mathrm{EP})$ & $\mathrm{h}_{\mathrm{q}}^{24}$ & $\mathrm{IC}^{5}$ \\
\hline 1 & $\mathrm{PCOZ}$ & $8,6^{* * * *}$ & 71 & $-0,723(0,177)$ & $0,073(0,265)$ & 5,48 & $65-75$ \\
\hline 1 & PTOT & $6,1^{*}$ & 71 & $-0,812(0,248)$ & $0,540(0,371)$ & 3,64 & $62-75$ \\
\hline 2 & PL & $5,87^{*}$ & 0 & $-0,005(0,011)$ & $0,062(0,1845)$ & 0,05 & $0-22$ \\
\hline 2 & PROFLOMB & $7,53 * *$ & 31 & $-2,043(0,547)$ & $0,42(0,1,14)$ & 9,91 & $17-45$ \\
\hline 2 & $\mathrm{AOL}$ & $6,43^{*}$ & 31 & $-1,419(0,402)$ & $0,001(0,84)$ & 8,89 & $15-46$ \\
\hline 2 & $\mathrm{pH} 45$ & $7,76^{* *}$ & 89 & $-0,116(0,029)$ & $0,015(0,547)$ & 9,41 & $85-120$ \\
\hline 3 & PP & $7,41 * *$ & 37 & $0,068(0,033)$ & $-0,192(0,015)$ & 1,68 & $28-56$ \\
\hline 12 & SH & $6,7^{*}$ & 92 & $-1,140(0,454)$ & $-2,023(0,711)$ & 2,79 & $89-99$ \\
\hline 14 & PPL & $5,34 *$ & 18 & $-0,132(0,043)$ & $-0,086(0,071)$ & 5,82 & $0-38$ \\
\hline 14 & INTEST & $7,27 * *$ & 107 & $-0,129(0,201)$ & $1,340(0,359)$ & 0,27 & $90-127$ \\
\hline 15 & ETL & $6,73^{*}$ & 88 & $0,979(0,952)$ & $1,704(0,598)$ & 1,72 & $76-92$ \\
\hline 15 & SH & $7,55^{* *}$ & 100 & $1,004(0,36)$ & $-1,21(0,543)$ & 2,17 & $66-115$ \\
\hline 15 & $\mathrm{AOL}$ & $7,95 * *$ & 112 & $-1,359(0,356)$ & $-0,415(0,638)$ & 8,18 & $97-127$ \\
\hline 15 & PCOPAL & $6,36^{*}$ & 88 & $-0,049(0,015)$ & $0,0315(0,021)$ & 3,04 & $71-98$ \\
\hline 15 & PPAL & $5,6^{*}$ & 88 & $-0,058(0,024)$ & $-0,083(0,033)$ & 1,86 & $76-96$ \\
\hline 15 & GOTEJ & $6,78^{*}$ & 101 & $-0,416(0,130)$ & $-0,469(0,199)$ & 3,08 & $94-115$ \\
\hline $\mathrm{X}$ & $\mathrm{L}^{*}$ & $10,5^{* *}$ & 111 & $-0,624(0,192)$ & - & 5,25 & $100-120$ \\
\hline $\mathrm{X}$ & $A^{*}$ & $11,9^{* *}$ & 111 & $0,254(0,073)$ & - & 6,07 & $97-130$ \\
\hline
\end{tabular}

*,** e ***significantivo a 5\% e $1 \%$ nível cromossômico, e a 5\% nível genômico, respectivamente; ${ }^{1}$ PROFLOMB profundidade de lombo $(\mathrm{mm}), \mathrm{AOL}$ - área de olho de lombo, $\left(\mathrm{cm}^{2}\right), \mathrm{SH}$ - maior espessura de toucinho na região da copa, na linha dorsolombar (mm), INTEST - comprimento total do intestino delgado(m), ETL - menor espessura de toucinho medida na região acima da última vértebra lombar, na linha dorsolombar $(\mathrm{mm}), \mathrm{PL}$ - peso do lombo $(\mathrm{Kg})$, PP - peso do pernil (Kg), PCOPAL - peso da copa sem pele e sem gordura (Kg), PPL - peso do pernil sem pele sem gordura $(\mathrm{Kg})$, PPAL - peso da paleta sem pele sem gordura $(\mathrm{Kg}), \mathrm{A}$ - índice de vermelho, $\mathrm{COZ}$ - perda por cozimento $(\%)$, PTOT - perda de peso total (perda de peso total = perda de peso por gotejamento + perda de peso por cozimento), (\%), pH45-pH45 minutos, GOTEJ - perda por gotejamento (\%) e L - luminosidade;

${ }^{2}$ posição em cM; ${ }^{3}$ Valores positivos dos efeitos aditivos indicam que os alelos da raça Piau causam aumento na característica avaliada, ${ }^{4}$ fração aditiva da variância fenotípica explicada pelo QTL $\left(\mathrm{h}^{2}{ }_{\mathrm{q}}=\mathrm{a}^{2} / 2 \sigma_{\mathrm{Y}}^{2}\right)$ em \%; ${ }^{5}$ intervalo de confiança em cM.

No presente trabalho, QTLs para características de carcaça e corte de carcaça foram associados, em sua maioria, aos alelos da linhagem comercial (Tab. 2), o que era esperado, uma vez que estes animais passaram por processo de seleção para melhorias dessas características.

$\mathrm{Na}$ região proximal do $\mathrm{SSC} 2$, região onde se localizou o QTL para peso do lombo $\left(h_{Q}^{2}=0,05\right.$; $\left.\mathrm{P}_{\mathrm{c}}<0,05, \mathrm{IC}=0-22 \mathrm{cM}\right)$, localiza-se o gene IGF2 (fator de crescimento semelhante à insulina 2), gene candidato a afetar crescimento muscular e deposição de gordura em suíno. Duthie et al. (2008), em cruzados Pietrain, Large White, Landrace e Leicoma (IC $=0-9,8 \mathrm{cM}$ ), Sanchez et al. (2006), em suínos comerciais (0cM), e Milan et al. (2002), em cruzados Meishan x Large White $(\mathrm{IC}=0-18 \mathrm{cM})$, também encontraram QTL para peso do lombo na região proximal do SSC2. Ainda no SSC2, encontrou-se QTL para PROFLOMB $(\mathrm{Pc}<0,01, \quad \mathrm{IC}=17-45)$ e $\mathrm{AOL}$ (Pc<0.05, IC=15-46). Os QTLs para PROFLOMB e AOL localizaram-se na mesma região do cromossomo 2, entre os marcadores SW2443 e SW240, podendo se tratar de um QTL 
com efeito pleiotrópico, ou seja, a variação de um gene se traduz em vários efeitos fenotípicos e explicaram consideravelmente a variação fenotípica da característica de $9,91 \%$ e $8,89 \%$, respectivamente (Tab. 2).

Liu et al. (2007) também encontraram QTL para AOL (20,7 cM) entre os marcadores SW2443 e SWR2157 em animais formados pelo cruzamento de suínos Duroc X Pietrain, enquanto Lee et al. (2003) encontraram QTL para AOL associado aos marcadores SW240 e ao gene MYOD (IC=42-57,4 cM).

A variação na localização do QTL para mesma característica ou ausência dele em diferentes populações ocorre devido ao fato de os estudos de mapeamento serem realizados em populações com distintas composições genéticas e/ou diferentes marcadores. Assim, o alelo do(s) gene(s) associado a um QTL pode ser diferente. Outra possibilidade é que o alelo-QTL pode não estar em fase de desequilíbrio de ligação com os marcadores avaliados nos diferentes estudos, sendo necessária, nos estudos de QTL, a validação destes em populações comerciais para serem usados em programas de seleção.

Os seis QTLs mapeados no SSC15 localizaramse na região distal do cromossomo (Tab. 2). O QTL para AOL $(\mathrm{F}=7,95 ; \mathrm{a}=-1,359 ; \mathrm{Pc}<0,01)$ localizou-se no intervalo de 97 a $127 \mathrm{cM}$, entre os marcadores SW936 e SW1262, o que explica, consideravelmente, a variação fenotípica da característica $\left(\mathrm{h}_{\mathrm{q}}^{2}=8,48 \%\right)$. Em região similar, Liu et al. (2007) encontraram QTL para AOL, em cruzados Duroc $X$ Pietrain, entre os marcadores SW936 e SW119 (IC=88,5-119,9). No entanto, Edwards et al. (2008), em uma população $\mathrm{F} 2$ formada por machos Duroc $\mathrm{X}$ fêmeas Pietrain ( $\mathrm{IC}=34,6-65,1 \mathrm{cM})$, e Wimmers et al. (2007), em cruzados Duroc X Pietrain $(\mathrm{IC}=39,8-88,5)$, encontraram QTL para AOL em região anterior ao presente trabalho.

QTLs significativos em nível de 5\% cromossômico para PCOPAL $\left(\mathrm{h}_{\mathrm{q}}^{2}=3,04\right.$, $\mathrm{F}=6,36)$ e QTL para PPAL $\left(\mathrm{h}_{\mathrm{q}}^{2}=1,86, \mathrm{~F}=5,6\right)$ também foram encontrados no SSC15. Esses QTLs localizaram-se entre os marcadores SW1989 e SW936 (88cM), indicando que, nesta região, pode haver um QTL pleiotrópico (Tab. 2).
Ainda no SSC15, encontraram-se um QTL para ETL $\left(\mathrm{Pc}<0,05 ; \mathrm{h}_{\mathrm{q}}^{2}=1,72\right)$ entre os marcadores SW1989 e SW936 (IC=76-92) e um QTL para SH $\left(\mathrm{Pc}<0,01 ; \mathrm{h}_{\mathrm{q}}^{2}=2,17\right)$ entre os marcadores SW1989 e SW1262. E, como era esperado, esses QTLs para espesura de toucinho foram associados aos alelos da raça Piau, suíno tipo banha. O intervalo de confiança para o QTL SH foi amplo, de 66 a $115 \mathrm{cM}$, podendo se tratar de mais de um QTL, necessitando, portanto, de maior investigação. Liu et al. (2007), em população formada por Duroc X Pietrain, na região entre o marcadore SW1111 e o marcador SW936 (marcador utilizado no presente estudo), também encontraram QTL para espessura de toucinho ( $\mathrm{IC}=39,8-88,5 \mathrm{cM}$ ).

QTL para PP $\left(\mathrm{h}_{\mathrm{q}}^{2}=1,68 ; \mathrm{Pc}<0,01 ; \mathrm{IC}=28-56\right)$ foi encontrado no SSC3 entre os marcadores S0206 e SW902. Em região similar, Stratil et al. (2006), em população formada por Meishan x Pietrain, encontraram QTL para PL. No entanto, Beeckmann et al. (2003) encontraram QTL para PP (IC=17,8-42,3 cM) em região próxima ao QTL para PP encontrado no presente estudo, usando população diferente (Meishan x Pietrain), mas um marcador em comum (S0206).

QTL para PPL $(\mathrm{Pc}<0,05)$ foi encontrado na região proximal do SSC14 a $18 \mathrm{cM}$, o que explica, de forma considerável, a variação fenotípica da característica $\left(\mathrm{h}_{\mathrm{q}}^{2}=5,82\right)$ entre os marcadores SW857 e SW210. No entanto, Dragos-Wendrich et al. (2003) encontraram QTL para PP a 65,4 cM $\quad\left(\mathrm{h}_{\mathrm{q}}^{2}=4,9 ; \mathrm{Pc}<0,05\right)$, em família Meishan x Pietrain, e a 74,5 $\mathrm{cM}\left(\mathrm{h}_{\mathrm{q}}^{2}=5,5\right.$; $\mathrm{P}<0,01)$, em família de suíno selvagem europeu $\mathrm{x}$ Pietrain. No SSC14, encontrou-se também um QTL para intestino $\left(\mathrm{h}_{\mathrm{q}}{ }_{\mathrm{q}}=0,27 ; \mathrm{Pc}<0,01\right)$.

QTL para espessura de toucinho $\mathrm{SH}\left(\mathrm{h}_{\mathrm{q}}{ }_{\mathrm{q}}=2,79\right.$; $\mathrm{a}=-1,140 ;$ Pc <0,05) também foi encontrado no SSC12, entre os marcadores SW1962 e S0106 ( $\mathrm{IC}=89-99 \mathrm{cM})$, contudo, inesperadamente, associado aos alelos da raça comercial, resultado contrário ao QTL para SH encontrado no SSC15 associado aos alelos da raça Piau. Esse resultado se torna inesperado, uma vez que os animais comerciais apresentaram uma redução média de $39 \%$ ( $\mathrm{p}<0,05)$ nas espessuras de toucinho avaliadas em relação aos animais Piau (Benevenuto Júnior, 2001). Na região distal do SSC12 (IC=64,7-108,3 cM), Liu et al. (2007) também encontraram QTL associado com 
espessura de toucinho $(101,2 \mathrm{cM})$ em cruzados Duroc x Pietrain.

No cromossomo 12, encontra-se o gene $\mathrm{GH}$ (hormônio do crescimento), candidato a influenciar várias características de importância econômica em suínos. Faria et al. (2006), na mesma população utilizada no presente estudo, encontraram um polimorfismo no gene $\mathrm{GH}$ (G316A) associado com o número de tetas direitas $(p=0,03)$, peso do coração $(p=0,04)$, peso do pulmão $(\mathrm{p}=0,05)$, comprimento de carcaça $(\mathrm{p}=0,04)$, peso total da paleta $(\mathrm{p}=0,07)$, peso da papada $(\mathrm{p}=0,01), \mathrm{pH}$ medido 24 horas postmortem $(\mathrm{p}=0,03)$ e perda por gotejamento $(\mathrm{p}=0,01)$. No presente estudo, encontrou-se QTL para algumas dessas carcaterísticas associadas ao gene $\mathrm{GH}$ em diferentes cromossomos.

Encontraram-se, ainda, importantes QTLs associados à qualidade da carne suína: QTL para perda de água na carne nos SSC1 e SSC15, pH 45 no SSC2 e cor da carne no SSCX. Os alelos da raça naturalizada Piau não foram associados com perda de água na carne, o que era esperado, uma vez que os animais da linhagem comercial apresentaram perda de peso total da carne (gotejamento + cozimento) $10,81 \%$ maior que os animais naturalizados (Benevenuto Júnior, 2001). Assim, o suíno Piau mostra-se como uma raça com variabilidade alélica a ser explorado em programas de melhoramento. Contudo, encontrou-se um QTL para maior $\mathrm{pH}$ a 45 minutos, associado aos alelos da linhagem comercial na região distal do $\operatorname{SSC} 2\left(\mathrm{~h}_{\mathrm{q}}^{2}=9,41\right.$; $\left.\mathrm{a}=-0,116 ; \mathrm{P}_{\mathrm{c}}<0,01\right)$.

Dentre os indicadores de qualidade de carne, as medidas de capacidade de retenção de água (perda por gotejamento, perda por cozimento e total) na populaçao F2 do presente estudo apresentaram correlação significativa $(p<0,01)$ com pH 45 (Benevenuto Júnior, 2001). Assim, o QTL para maior $\mathrm{pH}$ a 45 minutos no SSC2 também é de grande interesse a ser investigado, visto que apresenta correlação com importantes características associadas à qualidade da carne.

Segundo Jennen et al. (2007), CAST (calpastatina), CKMT2 (creatina quinase, mitocondrial 2), IGF2, LDHA (lactato desidrogenase A), MYOD1(diferenciação miogênica 1), PYGM (fosforilase, glicogênio, músculo), TTID (miotilina) são genes localizados no SSC2 e candidatos a influenciar características de $\mathrm{pH}$ e perda por gotejamento na carne suína. Wimmers et al. (2007) encontraram, após análises de expressão (Microarranjo, RTqPCR) e de polimorfismo, o gene EPOR (receptor de eritropoietina) como candidato a influenciar $\mathrm{pH} 24$ horas post-mortem $(\mathrm{P}<0,003) \mathrm{e}$ perda por cozimento em Longissumus dorsi em suínos cruzados Duroc e Pietrain. Lee et al. (2003) encontraram QTL para $\mathrm{pH} 24$ na região distal do SSC2 $(73 \mathrm{cM})$.

O QTL para PCOZ $\left(\mathrm{F}=8,6 ; \mathrm{h}_{\mathrm{q}}^{2}=5,48 ; \mathrm{a}=-0,783\right.$; $\mathrm{P}<0,05)$ localizou-se a $71 \mathrm{cM}$ no SSC1 e, como era esperado, na mesma região foi encontrado o QTL para PTOT = PGOTEJ + PCOZ (Fig. 1).

Liu et al. (2007) encontraram QTL para pH e cor da carne na região do MC4R (receptor de melanocortina 4) em cruzados Duroc-Pietrain. Vidal et al. (2006) encontraram associação do gene ME1 (enzima málica 1) com espessura de toucinho e $\mathrm{pH}$ muscular em suínos Landrace; essa enzima tem uma forte influência na gordura intramuscular, e grandes diferenças na sua atividade têm sido encontrada entre suínos Landrace e Ibéricos (Morales et al., 2002). Malek et al. (2001) encontraram QTL para PGOTEJ na região distal do SSC1 $(90 \mathrm{cM})$ para uma população formada por Berkshire $\mathrm{X}$ Yorkshire.

No SSC15, encontrou-se um QTL para PGOTEJ $\left(\mathrm{h}_{\mathrm{q}}^{2}=3,08 ; \mathrm{a}=-0,416 ; \mathrm{Pc}<0,05\right)$ localizado a 101 cM, próximo ao marcador SW936. Nesta região, encontra-se o gene RN/ PRKAG3 (proteína quinase ativada por AMP, subunidade não catalítica gama 3), candidato a influenciar esse QTL. Isto é possível, tendo em vista que diferentes estudos identificaram substituições não sinônimas neste gene associadas com $\mathrm{pH}$, cor e capacidade de retenção de água na carne suína (Milan et al., 2000; Ciobanu et al., 2001). Também em região distal do SSC15 $(92,5 \mathrm{cM})$, Edwards et al. (2008) encontraram QTL associado à perda de água na carne suína (QTL para PCOZ). No entanto, Thomsen et al. (2004), em região proximal do SSC15, $(65 \mathrm{cM})$, encontraram QTL para PGOTEJ em Berkshire X Yorkshire, e Rohrer et al. (2005) a 57 cM, entre Duroc X Landrace. 


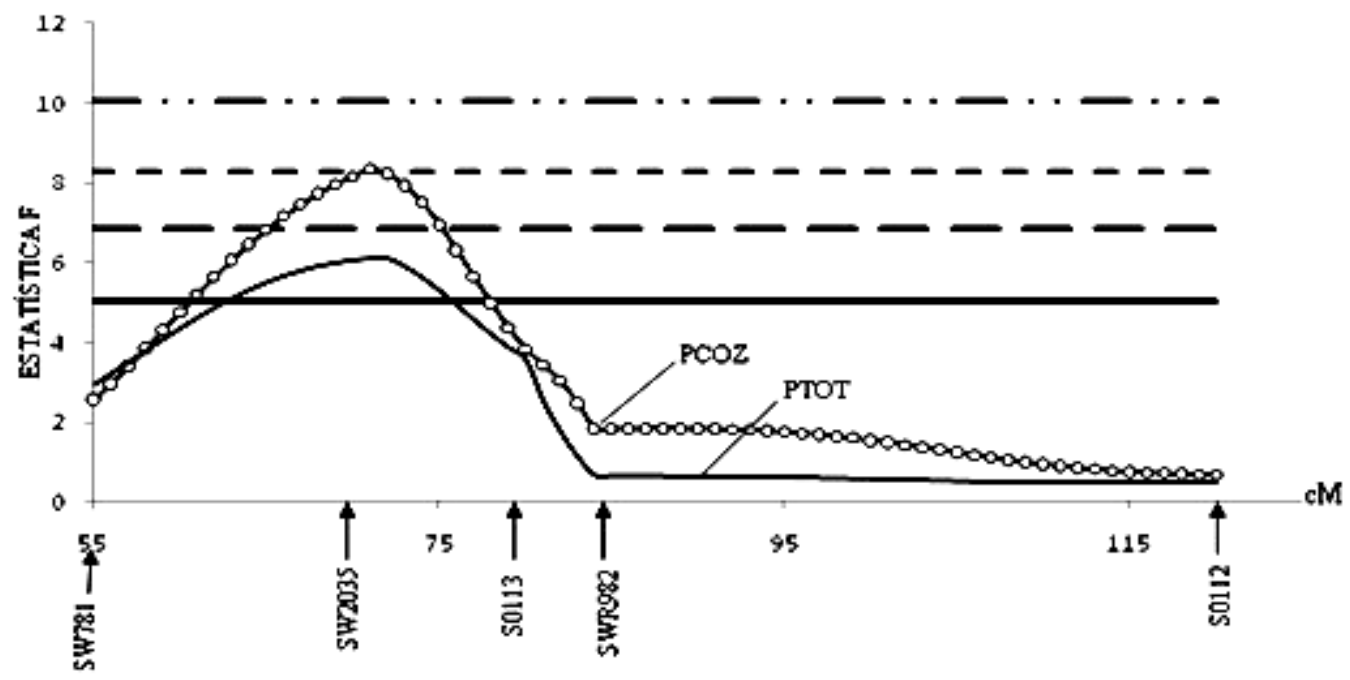

Figura 1. Estimativas dos valores de F para perda por cozimento (PCOZ) e perda de peso total (PTOT) no SSC 1. As linhas horizontais indicam os níveis de significância ao longo do cromossomo: $5 \%$ em nível cromossômico (-), $1 \%$ em nível cromossômico (- -), 5\% em nível genômico (- - -) e $1 \%$ em nível genômico ( $-\cdots)$. A posição dos marcadores é indicada por setas.

Segundo Lindahl et al. (2001), o aumento no teor de lipídeos leva a um aumento na concentração de metamioglobina $(\mathrm{MMb})$, o que provocaria um aumento nos índices de vermelho $\left(\mathrm{A}^{*}\right)$ e uma diminuição na luminosidade $\left(\mathrm{L}^{*}\right)$. Corroborando com essas afirmativas, encontrou-se um QTL para $A^{*}\left(h^{2}{ }_{q}=6,07 ; a=0,25 ; P c<0,05\right)$ associado aos alelos da raça Piau, tipo banha, e um QTL para $L^{*}\left(h^{2}{ }_{q}=5,25 ; a=-0.624 ; P c<0,01\right)$ associado aos alelos da linhagem comercial, ambos a 111 cM no SSCX. QTLs para A* no SSCX também foram encontrados por Pérez-Enciso et al. (2002) a $50 \mathrm{cM}$ em cruzados Ibéricos X Landrace. Ma et al. (2009), além do QTL para $\mathrm{A}^{*}$ a $87 \mathrm{cM}$, encontraram também QTL para L* a 81,3 cM em cruzados Duroc X suínos chineses Erhualian.

\section{CONCLUSÕES}

QTLs associados a importantes características econômicas, com efeitos aditivos significativos e $\mathrm{h}_{\mathrm{q}}^{2}$ expressivas, foram encontrados na população F2 gerada pelo cruzamento entre suínos machos da raça naturalizada Piau e fêmeas comerciais.

\section{AGRADECIMENTOS}

Ao Prof. Max F. Rothschild, coordenador do US Pig Genome Project, pela doação dos primers microssátelites.

\section{REFERÊNCIAS}

BAND, G.O.; GUIMARÃES, S.E.F.; LOPES, P.S. et al. Relationship between the porcine stress syndrome gene and pork quality trait in F2 pigs resulting from divergent crosses. Genet. Mol. Biol., v.8, p.88-91, 2005a.

BAND, G.O.; GUIMARÃES, S.E.F.; LOPES, P.S. et al. Relationship betweem the porcine stress Syndrome gene and carcass and performance trait in F2 pigs resulting from divergent crosses. Genet. Mol. Biol., v.8, p.9296, 2005b.

BEECKMANN, P.; SCHRÖFFEL JR, J.; MOSER, G. et al. Linkage and QTL mapping for Sus scrofa Chromosome 3. J. Anim. Breed. Genet., v.120, p.20-27, 2003. 
BENEVENUTO JÚNIOR, A.A. Avaliação de rendimento de carcaça e de qualidade da carne de suínos comerciais, de raça nativa e cruzados. 2001. 98f. Dissertação (Mestrado em Ciência e Tecnologia de Alimentos) Universidade Federal de Viçosa, 2001.

BOTSTEIN, D.; WHITE, R.L.; SKOLMICK, H. et al. Construction of a genetic linkage map in man using restriction fragment length polymorphism. Am. J. Hum. Genet., v.32, p.314$331,1980$.

CHURCHILL, G.A.; DOERGE, R.W. Empirical threshold values for quantitative trait mapping. Genet., v.138, p.963-971, 1994.

CIOBANU D.; BASTIAANSEN J.; MALEK M., et al. Evidence for new alleles in the protein kinase adenosine monophosphate activated $\gamma 3$ subunit gene associated with low glycogen content in pig skeletal muscle and improved meat quality. Genet., v.159, p.1151-1162, 2001.

DRAGOS-WENDRICH, M.; MOSER, G.; BARTENSCHLAGER, $\mathrm{H}$. et al. Linkage and QTL mapping for Sus scrofa chromosome 10. Journal Anim. Breed. Genet., v.120, p.82-88, 2003.

DUTHIE, C.; SIMM, G.; DOESCHL-WILSON, A. et al. Quantitative trait loci for chemical body composition traits in pigs and their positional associations with body tissues, growth and feed intake. Anim. Genet., v.39, p.130-140, 2008.

EDWARDS, D.B.; ERNST, C.W., RANEY, N.E. et al. Quantitative trait locus mapping in an F2 Duroc $x$ Pietrain resource population: II.Carcass and meat quality traits. J. Anim. Sci., v.86, p.254-266, 2008.

FARIA, D.A.; GUIMARÃES, S.E.F.; LOPES, P.S. et al. Association between G316A growth hormone polymorphism and economic traits in pigs. Genet. Mol. Biol., v.29, p.634-640, 2006.

GREEN, P.; FALLS, K.; CROOKS, S. Documentation for CRIMAP, St. Louis, Mo.: Washington Univ. School of Medicine, 1990. <http://linkage.rockefeller.edu/soft/crimap>. Acessado em: 20 abr.2010

GUIMARÃES, S.E.F.; LOPES, P.S. Uso de recursos genéticos nativos no mapeamento genético de suínos. Ação Ambiental, v.15, p.2728, 2001.
JENNEN， D.G.J.; BRINGS，A.D.; LIU， G. Genetic aspects concerning drip loss and waterholding capacity of porcine meat. J. Anim. Breed. Genet., v.124, p.2-11, 2006.

KALINOWSKI, S.T.; TAPER, M.L.; MARSHALL, T.C. Revising how the computer program CERVUS accommodates genotyping error increases success in paternity assignment. Mol. Ecol., v.16, p.1099-1006, 2007.

KNOTT, S.A.L.; MARKLUND, C.S.; HALEY, K. et al. Multiple marker mapping of quantitative trait loci in a cross between outbred wild boar and Large White pigs. Genetics, v.149, p.10691080, 1998.

LEE, C.; CHUNG, Y.; KIM, J.H. Quantitative trait loci mapping for fatty acid contents in the backfat onporcine chromosomes 1, 13, and 18 . Mol. Cell, v.15, p.62-7, 2003.

LIU, G.; JENNEN, D.G.J.; THOLEN, E. et al. A genome scan reveals QTL for growth, fatness, leanness and meat quality in a Duroc-Pietrain resource population. Anim. Genet., v.38, p.241$52,2007$.

LINDAHL, G.; LUNDSTROM, K.; TORNBERG, E. Contribution of pigment content, myoglobin forms and internal reflectance to the colour of pork loin and ham from pure breed pigs. Meat Sci., v.59, p.141-151, 2001.

MA, J.; REN, J.; GUO, Y. Genome-wide identification of quantitative trait loci for carcass composition and meat quality in a large-scale White Duroc x Chinese Erhualian resource population. Anim. Genet., v.5, p.637-647, 2009.

MALEK, M.; DEKKERS, J.C.M.; LEE, H.K. et al. A molecular genome scan analysis to identify chromosomal regions influencing economic traits in the pig. II. Meat and muscle composition. Mamm. Genome, v.12, p.637-645, 2001.

MILAN, D.; BIDANEL, J.P.; IANNUCCELLI, N. et al. Detection of quantitative trait loci for carcass composition traits in pigs. Genet. Sel. Evol., v.34, p.705-28, 2002.

MILAN D.; JEON J.T.; LOOFT C. et al. A mutation in PRKAG3 associated with excess glycogen content in pig skeletal muscle. Science, v.288, p.1248-1251, 2000. 
MORALES, J.; PEREZ, J.F.; MARTIN-ORUE, S.M. Large bowel fermentation of maize or sorghum-acorn diets fed as a different source of carbohydrates to Landrace and Iberian pigs. $\mathrm{Br}$. J. Nutr., v.88, p.489-98, 2002.

PAIXÃO, D.M.; SILVA FILHO, M.I.; PEREIRA, M.S. et al. Quantitative trait loci for carcass, internal organ and meat quality traits on porcine chromosomes 16, 17 and 18. Genet. Mol. Biol., v.31, p.898-901, 2008a.

PAIXÃO, D.M.; GUIMARÃES, S.E.F.; SILVA FILHO, M.I. et al. Detecção de locos de características quantitativas nos cromossomos 16, 17 and 18 de suínos. Rev. Bras. Zootec., v.37, p.1781-1787, 2008b.

PEIXOTO, J.O.; FARIA, D.A.; SILVA, P.V. et al. Association between leptin gene single nucleotide polymorphisms and carcass traits in pigs. Rev. Bras. Zootec., v.38, p.271-276, 2009.

PÉREZ-ENCISO, M.; CLOP, A.; NOGUERA, J.L. et al. A QTL on pig chromssome 4 affects fatty acid metabolism: Evidence from Iberian by landrace intercross. J. Anim. Sci., v.78, p.25252531, 2000.

ROHRER,G.A.; THALLMAN, R.M; SHACKELFORD, S. A genome scan for loci affecting pork quality in a duroc-Landrace F2 population. Anim. Genet., v.37, p.17-27, 2005.

SANCHEZ, M.P.; RIQUET, J.; IANNUCCELLI, N. et al. Effects og quantitative trait loci on cgromosomes 1,2,4, and 7 on growth carcass, and meat quality traits in backcross Meishan $\mathrm{x}$ Large White pigs. J. Anim. Sci., v.84, p.526-537, 2006.
SEATON, G.; HERNANDEZ J.; GRUNCHEC J.A. et al. Proceeding of the 8th World Congress On Genetics Applied to Livestock Production. Belo Horizonte, Brasil 2006. A Grid Portal for QTL Mapping of Compute Intensive Datasets

SERÃO, N.; RIBEIRO, A.; VERARDO, L. et al. Candidate gene expression and intramuscular fat contente in pigs. Anim. Breed. Genet., v.128, p.28-34, 2010.

STRATIL, A.; VAN POUCKE, M.; BARTENSCHLAGER, H. et al. Porcine OGN and ASPN: mapping, polymorphisms and use for quantitative trait loci identification for growth and carcass traits in a Meishan $x$ Pietrain intercross. Anim. Genet., v.37, p.415-418, 2006.

THOMSEN, H.; LEE, H.K.; ROTHSCHILD, M.F. et al. Characterization of quantitative trait loci for growth and meat quality in a cross between commercial breeds of swine. J. Anim. Sci., v.82, p.2213-28, 2004.

VIDAL, O.; VARONA, L.; OLIVER, M.A. Malic enzyme 1 genotype is associated with backfat thickness and meat quality traits in pigs. Anim. Genet., v.37, p.28-32, 2006.

WIMMERS, K.; MURANI, E.; TE PAS, M.F. et al. Associations of functional candidate genes derived from gene-expression profiles of prenatal porcine muscle tissue with meat quality and muscle deposition. Anim. Genet., v.38, p.474-84, 2007. 